\title{
Korean Guidelines for Diagnosis and Management of Interstitial Lung Diseases: Part 4. Cryptogenic Organizing Pneumonia
}

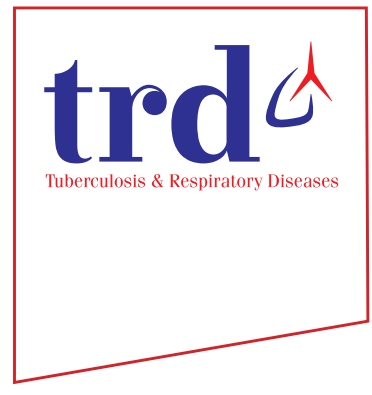

\author{
Sue In Choi, M.D., Ph.D. (®), Won Jai Jung, M.D., Ph.D. and Eun Joo Lee, M.D., Ph.D.(1) \\ Division of Respiratory, Allergy, and Critical Care Medicine, Department of Internal Medicine, Korea University College of \\ Medicine, Seoul, Republic of Korea
}

Cryptogenic organizing pneumonia (COP) is a type of idiopathic interstitial pneumonia with an acute or subacute clinical course. Bilateral lung consolidations located in the subpleural area and bronchovascular bundle are the most common findings on chest high-resolution computed tomography. The pathologic manifestations include granulation tissue in the alveoli, alveolar ducts, and bronchioles. COP responds fairly well to glucocorticoid monotherapy with rapid clinical improvement, but recurrence is common. However, treatment with combined immunosuppressant agents is not recommended, even if the COP patient does not respond to glucocorticoid monotherapy with expert opinion.

Keywords: Cryptogenic Organizing Pneumonia; Glucocorticosteroid; High-Resolution Computed Tomography

\section{Introduction}

Cryptogenic organizing pneumonia (COP) is a disease entity and a type of idiopathic interstitial pneumonia (IIP). COP was previously designated as bronchiolitis obliterans organizing pneumonia (BOOP), but the BOOP nomenclature has since been discarded to avoid a misleading association with airway disease $\mathrm{e}^{1,2}$. The differential diagnosis of COP from other etiologies is confirmed by identifying the organizing pneumonia pattern on lung biopsy.

Address for correspondence: Eun Joo Lee, M.D., Ph.D.

Division of Respiratory, Allergy, and Critical Care Medicine, Department of Internal Medicine, Korea University Anam Hospital, Korea University College of Medicine, Anam-ro 73, Seongbuk-gu, Seoul 02841, Republic of Korea

Phone: 82-2-920-5048, Fax: 82-2-929-2045

E-mail: nanjung@korea.ac.kr

Received: Feb. 7, 2021

Revised: Apr. 11, 2021

Accepted: May. 19, 2021

Published online: May. 20, 2021

(9) It is identical to the Creative Commons Attribution Non-Commercial License (http://creativecommons.org/licenses/by-nc/4.0/).

\section{History}

COP was first described in the 1980s by Davison et al. ${ }^{3}$ and Epler et al. ${ }^{4}$ as COP and BOOP, respectively. They described an illness similar to the common cold, but which (1) subacutely progressed for 4-10 weeks, (2) histologically showed intra-alveolar and alveolar duct consolidation, (3) responded fairly well to glucocorticosteroid therapy, and (4) frequently recurred. In 1997, Muller and Coiby ${ }^{5}$ classified idiopathic BOOP as an independent disease among IIPs according to chest high-resolution computed tomography (HRCT) and pathologic findings. In 2002, the American Thoracic Society (ATS) and European Respiratory Society (ERS) categorized COP as a form of IIP different from idiopathic pulmonary fibrosis. Specifically, the ATS/ERS classification system recommended using the term COP, as BOOP could be erroneously misclassified as an airway disease and may not histologically present with bronchiolitis obliterans ${ }^{1}$. The revised 2013 ATS/ ERS classification used the term COP instead of BOOP and defined the disease as having an acute or subacute course. COP and BOOP have been used simultaneously for some time, and some studies employed the term "idiopathic BOOP" to differentiate illnesses of unknown etiology from other illnesses with secondary causes. 


\section{Epidemiology}

To the best of our knowledge, there have been no studies on the prevalence or incidence of COP. However, several retrospective cohort studies have estimated a COP incidence of 1.1 cases per 100,000 persons $^{6}$. The prevalence was estimated at $3 \%$ among patients with interstitial lung disease (ILD), including those with connective tissue disease-related ILD and idiopathic ILD ${ }^{7}$. According to a 2008 national study by the Korean Academy of Tuberculosis and Respiratory Diseases, COP was detected in $8.5 \%$ of 2,186 IIP subjects and was the third most common disease among them ${ }^{8}$. COP usually occurs in the sixth and seventh decades of life. COP appears to have no distinct predilection according to sex. Although there have been some discrepancies among previous reports, nonsmokers were more common among COP patients than current smokers $^{1,6,9-11}$.

\section{Clinical Manifestation and Diagnosis}

\section{Clinical manifestation}

Previous studies have shown that the symptoms of COP lasted for less than three months on average, and followed an acute or subacute course. COP patients typically present with cough, dyspnea, and fever, and crackles are commonly heard on auscultation, whereas wheezing lung sounds are rarely noted. On pulmonary function tests, restrictive ventilatory defects and a decrease in the carbon monoxide diffusing capacity $\left(\mathrm{DL}_{\mathrm{CO}}\right)$ are typically observed ${ }^{10,12-15}$. However, the manifestations of organizing pneumonia can be seen in several conditions, such as infectious lung disease, inflammatory bowel disease, connective tissue disease, myeloproliferative disorder, graft-versus-host disease, drug reactions, or after undergoing radiation therapy. Of note, about half of the IIP patients were initially diagnosed with infectious lung disease and unsuccessfully treated with antibiotics; they were not correctly diagnosed until a lung biopsy was obtained ${ }^{12,16}$. Patients with infectious lung disease often present with similar clinical manifestations, such as cough, dyspnea, fever, general weakness, and chest computed tomography showing parenchymal consolidation, which obscures the differential diagnosis. One study reported that various bacteria, such as Streptococcus pneumoniae, Mycoplasma pneumoniae, Pseudomonas, Legionella, Pneumocystis jiroveci, and Nocardia, can cause organizing pneumonia ${ }^{13}$. Additionally, hypersensitivity pneumonitis, IIPs, and chronic eosinophilic pneumonitis are often accompanied by COP, requiring a thorough diagnostic evaluation. Therefore, when COP is suspected, careful history-taking is needed to differentially evaluate infectious, drug-induced, or any other etiologies. Furthermore, a multidisciplinary approach involving a pulmonologist, radiologist, and pathologist is necessary ${ }^{2}$. A comprehensive differential diagnosis is shown in Table 1.

\section{Pulmonary function test}

A restrictive ventilator defect is common in COP and the forced vital capacity is decreased mildly or moderately from $60 \%$ to $70 \%$. However, an obstructive component (with a restrictive pattern) can also accompany the common symptoms or can occur in isolation in $10-30 \%$ of the patients. $\mathrm{A} \mathrm{DL}_{\mathrm{CO}}$ decrease of $50 \%-70 \%$ is occasionally observed ${ }^{9,12-14}$.

\section{Radiologic findings}

On chest HRCT, consolidation along the subpleural area and bronchovascular bundle was the most common finding and was noted in nearly half of the cases, mostly bilaterally, and usually invaded the lower portion of the lungs ${ }^{9,12,14,16-18}$. Ground-glass opacity (GGO) is also frequently seen with an irregular distribution and concomitant consolidation, but sometimes is the sole feature ${ }^{19,20}$. Alternatively, perilobular opacity and a reversed halo sign (where the central GGO is surrounded by consolidation) were noted in $57 \%$ and $20 \%$ of patients, respectively ${ }^{21}$. Consolidation can appear as a unifocal or cavitary shape and rarely, as a large nodule or mass. Honeycombing or reticular lesions are rare. Some pulmonary lesions can migrate or even resolve spontaneously during follow-up. One retrospective study from Korea showed consolidation and GGO as the most common findings, mostly involving the lower lungs (Figure 1$)^{20}$.

\section{Bronchoscopy}

Bronchoalveolar lavage fluid analysis showed that the lymphocytic fraction increased by more than $25 \%$ in most cases, and some subjects showed a decrease in the $\mathrm{CD} 4 / \mathrm{CD} 8$ ratio,

Table 1. Differential diagnosis of cryptogenic organizing pneumonia

\begin{tabular}{|l|}
\hline \multicolumn{1}{|c|}{ Diagnosis } \\
\hline Infectious diseases \\
\hline Drug reaction \\
\hline Hypersensitivity pneumonitis \\
\hline Inflammatory bowel disease \\
\hline Aspiration pneumonia \\
Radiation pneumonitis \\
Chronic eosinophilic pneumonitis \\
Hematologic malignancy \\
\hline Organ transplantation (hematopoietic cells, liver, lung) \\
Other idiopathic interstitial pneumonias \\
\hline
\end{tabular}




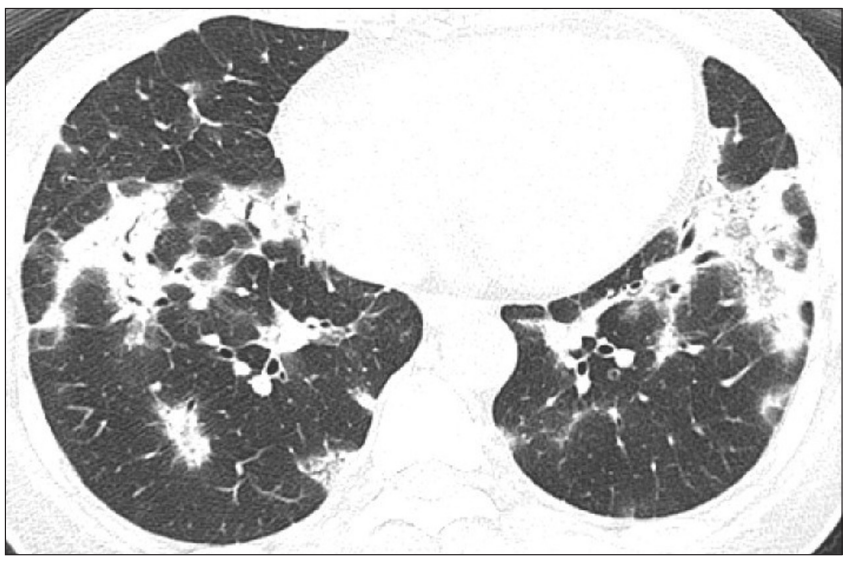

Figure 1. Bilateral consolidations and some ground-glass opacities are noted. These findings are commonly distributed in the subpleural or peribronchial areas. Air bronchogram is also noted in the consolidation area.

but these findings were nonspecific and played an auxiliary role in differential diagnosis ${ }^{10,11,22}$. Specifically, an elevated neutrophilic fraction requires discrimination from organizing pneumonia with an infectious etiology.

\section{Lung biopsy}

Lung biopsy is essential for confirmative diagnosis. Granulation tissue with Masson's bodies noted in the alveoli, alveolar duct, and some bronchioles are typical findings (Figure 2). In some cases, polyps are also present in the bronchiolar lumen. These characteristics indicate organizing pneumonia a finding seen with a patchy distribution, but structural deformities occur only infrequently. Interstitial fibrosis, granuloma, necrosis, vasculitis, and hyaline membrane are rare and suggest other underlying disorders ${ }^{1,23}$. Biopsy via surgery is the diagnostic standard. While transbronchial lung biopsy (TBLB) is not recommended for other IIPs, studies have shown some potential of TBLB in diagnosing COP, despite the limitation that the number of biopsy specimens was insufficient in most cases $^{9,10,14-16,18}$.

\section{Treatment}

There have been no studies comparing glucocorticoid monotherapy and placebo for COP treatment. However, several studies have reported rapid clinical improvement after glucocorticoid steroid treatment. The starting dosage for methylprednisolone or prednisone ranges from $0.5-1 \mathrm{mg} /$ $\mathrm{kg}$, with gradual tapering after a few weeks ${ }^{10,14,17}$. There is no established treatment duration, but six months to one year is recommended ${ }^{9,24}$. Recurrence is frequent, with a rate ranging from $13 \%$ to $58 \%$, and is associated with delayed glucocor-

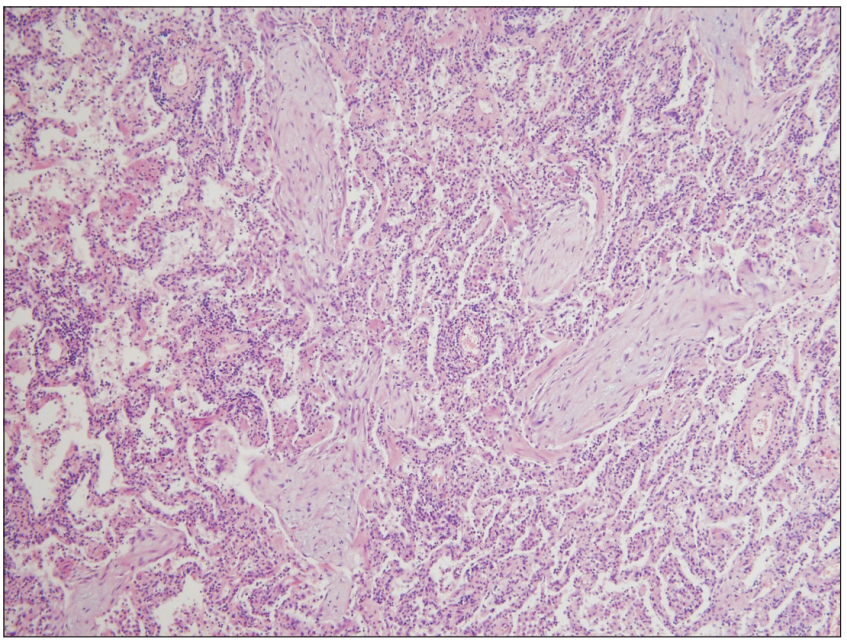

Figure 2. The alveolar duct and alveolar spaces are filled with polypoid granulation tissue or Masson's bodies $(\mathrm{H} \& \mathrm{E}, \times 100)$.

ticosteroid management ${ }^{9}$, insufficient glucocorticosteroid dosage, and short glucocorticosteroid treatment duration ${ }^{11}$. Nevertheless, the therapeutic response to glucocorticosteroids after recurrence is still favorable. According to Lazor et al. ${ }^{9}$, retreatment after recurrence with a dosage of $<20 \mathrm{mg} /$ day with an increase to $20 \mathrm{mg}$ /day or higher (e.g., average 40 $\mathrm{mg} /$ day) yielded similar clinical outcomes, but complications were more frequent as the dosage increased, suggesting that a retreatment dose of $20 \mathrm{mg}$ /day with gradual tapering is the optimal management strategy. Macrolide antibiotics ${ }^{25-27}$ and several immunosuppressants, such as cyclophosphamide ${ }^{13,28}$, cyclosporine $^{29}$, and azathioprine, have been introduced as glucocorticosteroid-sparing agents, but their efficacy is unknown, and only case reports of these treatments have been presented.

\section{Natural Course and Prognosis}

The response to glucocorticosteroids is generally good, and most COP cases resolve completely, but the recurrence rate is considerably high. Lazor et al. ${ }^{9}$ reported that $58 \%$ of the patients with COP experienced recurrence after glucocorticosteroid treatment, and $27 \%$ had more than two recurrence episodes. Most patients experienced recurrence within one year, and the most important factor predicting recurrence was a delay of $>16$ weeks after symptom development. A study by Cazzato et al. ${ }^{11}$, which also included secondary interstitial pneumonia cases, found that $26 \%$ of the patients had a verified recurrence, and patients who received a lower glucocorticosteroid dose or a shorter administration period were more susceptible to recurrence. Non-responsiveness to glucocorticosteroid treatment occurred in $12 \%-22 \%$ of patients with COP. However, the likelihood of the rapid progression to respi- 
ratory failure or death was rare $(<5 \%)^{10,11,22}$.

\section{Authors' Contributions}

Conceptualization: Choi SI, Lee EJ. Methodology: Choi SI, Lee EJ. Formal analysis: Choi SI, Lee EJ, Jung WJ. Writing original draft preparation: Choi SI, Lee EJ. Writing - review and editing: Jung WJ. Approval of final manuscript: all authors.

\section{Conflicts of Interest}

No potential conflict of interest relevant to this article was reported.

\section{Funding}

No funding to declare.

\section{References}

1. American Thoracic Society; European Respiratory Society. American Thoracic Society/European Respiratory Society International Multidisciplinary Consensus Classification of the Idiopathic Interstitial Pneumonias. This joint statement of the American Thoracic Society (ATS), and the European Respiratory Society (ERS) was adopted by the ATS board of directors, June 2001 and by the ERS Executive Committee, June 2001. Am J Respir Crit Care Med 2002;165:277-304.

2. Travis WD, Costabel U, Hansell DM, King TE Jr, Lynch DA, Nicholson AG, et al. An official American Thoracic Society/ European Respiratory Society statement: update of the international multidisciplinary classification of the idiopathic interstitial pneumonias. Am J Respir Crit Care Med 2013;188: 733-48.

3. Davison AG, Heard BE, McAllister WA, Turner-Warwick ME. Cryptogenic organizing pneumonitis. Q J Med 1983;52:38294.

4. Epler GR, Colby TV, McLoud TC, Carrington CB, Gaensler EA. Bronchiolitis obliterans organizing pneumonia. N Engl J Med 1985;312:152-8.

5. Muller NL, Coiby TV. Idiopathic interstitial pneumonias: highresolution CT and histologic findings. Radiographics 1997;17: 1016-22.

6. Gudmundsson G, Sveinsson O, Isaksson HJ, Jonsson S, Frodadottir H, Aspelund T. Epidemiology of organising pneumonia in Iceland. Thorax 2006;61:805-8.

7. Hyldgaard C, Hilberg O, Muller A, Bendstrup E. A cohort study of interstitial lung diseases in central Denmark. Respir Med 2014;108:793-9.
8. Scientific Committee of the Korean Academy of Tuberculosis and Respiratory Diseases. 2008 National survey of idiopathic interstitial pneumonia in Korea. Tuberc Respir Dis 2009;66:141-51.

9. Lazor R, Vandevenne A, Pelletier A, Leclerc P, Court-Fortune I, Cordier JF. Cryptogenic organizing pneumonia: characteristics of relapses in a series of 48 patients. The Groupe d'Etudes et de Recherche sur les Maladles "Orphelines" Pulmonaires (GERM"O”P). Am J Respir Crit Care Med 2000;162:571-7.

10. Li Y, Li Y, Han F, Yu H, Yang T, Li H, et al. Cryptogenic organising pneumonia: clinical, pathological, and prognostic analysis of 27 cases. Int J Clin Exp Med 2016;9:6911-9.

11. Cazzato S, Zompatori M, Baruzzi G, Schiattone ML, Burzi M, Rossi A, et al. Bronchiolitis obliterans-organizing pneumonia: an Italian experience. Respir Med 2000;94:702-8.

12. Alasaly K, Muller N, Ostrow DN, Champion P, FitzGerald JM. Cryptogenic organizing pneumonia: a report of 25 cases and a review of the literature. Medicine (Baltimore) 1995;74:20111.

13. Basarakodu KR, Aronow WS, Nair CK, Lakkireddy D, Kondur A, Korlakunta H, et al. Differences in treatment and in outcomes between idiopathic and secondary forms of organizing pneumonia. Am J Ther 2007;14:422-6.

14. Fonseca AL, Meruje M, Barata F, Martins Y. Bronchiolitis obliterans organizing pneumonia: experience of a pulmonology ward. Rev Port Pneumol 2007;13:301-18.

15. Han SK, Yim JJ, Lee JH, Yoo CG, Chung HS, Shim YS, et al. Bronchiolitis obliterans organizing pneumonia in Korea. Respirology 1998;3:187-91.

16. Sen T, Udwadia ZF. Cryptogenic organizing pneumonia: clinical profile in a series of 34 admitted patients in a hospital in India. J Assoc Physicians India 2008;56:229-32.

17. Okada F, Ando Y, Honda K, Tanoue S, Matsumoto S, Mori H. Comparison of pulmonary CT findings and serum KL-6 levels in patients with cryptogenic organizing pneumonia. $\mathrm{Br} \mathrm{J}$ Radiol 2009;82:212-8.

18. Sveinsson OA, Isaksson HJ, Sigvaldason A, Yngvason F, Aspelund T, Gudmundsson G. Clinical features in secondary and cryptogenic organising pneumonia. Int J Tuberc Lung Dis 2007;11:689-94.

19. Lee KS, Kullnig P, Hartman TE, Muller NL. Cryptogenic organizing pneumonia: CT findings in 43 patients. AJR Am J Roentgenol 1994;162:543-6.

20. Lee JW, Lee KS, Lee HY, Chung MP, Yi CA, Kim TS, et al. Cryptogenic organizing pneumonia: serial high-resolution CT findings in 22 patients. AJR Am J Roentgenol 2010;195:91622 .

21. Sverzellati N, Lynch DA, Hansell DM, Johkoh T, King TE Jr Travis WD. American Thoracic Society-European Respiratory Society classification of the idiopathic interstitial pneumonias: advances in knowledge since 2002. Radiographics 2015;35:1849-71.

22. Oymak FS, Demirbas HM, Mavili E, Akgun H, Gulmez I, 
Demir R, et al. Bronchiolitis obliterans organizing pneumonia: clinical and roentgenological features in 26 cases. Respiration 2005;72:254-62.

23. Taniguchi H, Kondoh Y. Acute and subacute idiopathic interstitial pneumonias. Respirology 2016;21:810-20.

24. Lohr RH, Boland BJ, Douglas WW, Dockrell DH, Colby TV, Swensen SJ, et al. Organizing pneumonia. Features and prognosis of cryptogenic, secondary, and focal variants. Arch Intern Med 1997;157:1323-9.

25. Ding QL, Lv D, Wang BJ, Zhang QL, Yu YM, Sun SF, et al. Macrolide therapy in cryptogenic organizing pneumonia: a case report and literature review. Exp Ther Med 2015;9:829-34.

26. Lee J, Cha SI, Park TI, Park JY, Jung TH, Kim CH. Adjunctive effects of cyclosporine and macrolide in rapidly progressive cryptogenic organizing pneumonia with no prompt response to steroid. Intern Med 2011;50:475-9.

27. Pathak V, Kuhn JM, Durham C, Funkhouser WK, Henke DC. Macrolide use leads to clinical and radiological improvement in patients with cryptogenic organizing pneumonia. Ann Am Thorac Soc 2014;11:87-91.

28. Vasu TS, Cavallazzi R, Hirani A, Sharma D, Weibel SB, Kane GC. Clinical and radiologic distinctions between secondary bronchiolitis obliterans organizing pneumonia and cryptogenic organizing pneumonia. Respir Care 2009;54:1028-32.

29. Lee JH, Park MJ, Kim YH, Park BJ, Oh WT, Lee MY, et al. Two cases of bronchiolitis obliterans organizing pneumonia treated with steroid and cyclosporine therapy. Tuberc Respir Dis 2005;59:315-20. 